\title{
Satélites artificiais e Torques Externos: Análise do ângulo de Aspecto Solar
}

\author{
$\underline{\text { Tatiane S. Pelosi }}^{* 1}$, Maria Cecília Zanardi ${ }^{2}$, Valcir Orlando ${ }^{3}$ \\ ${ }^{1}$ Engenhaira de Materiais, FEG, UNESP - Campus de Guaratinguetá, SP \\ E-mail: tatiane_pelosi@hotmail.com \\ ${ }^{2}$ Universidade Federal do ABC, Santo André, SP \\ E-mail: cecilia@ feg.unesp.br \\ ${ }^{3}$ Centro de Controle de Satélites, INPE, São Jose dos Campos, SP \\ E-mail: valcir@ccs.inpe.br
}

\begin{abstract}
RESUMO
O ângulo de aspecto solar é o ângulo formado entre a direção de incidência dos raios solares sobre o satélite e a direção do eixo de rotação do satélite. A obtenção do ângulo de aspecto solar é de suma importância para o bom desempenho da missão, pois os satélites carregam equipamentos que podem se danificar devido ao superaquecimento causado pela incidência dos raios solares. Cada satélite possui uma faixa angular ótima em que esta incidência não prejudica os equipamentos a bordo.

O estudo deste ângulo tem sido importante para o bom desempenho dos Satélites Brasileiros de Coleta de Dados (SCD1 e SCD2). Para o SCD1 a faixa de segurança varia de 60 a 90 graus e para o SCD2 esta faixa é mais restrita variando de 80 a 100 graus.

Neste trabalho é considerado satélite estabilizado por rotação, cujo eixo de rotação coincide com o eixo de maior momento principal de inércia deste satélite. O posicionamento deste eixo em relação a um sistema inercial é dado pelo ângulo de declinação $\delta$ (formado entre o eixo de rotação e o plano inercial) e o ângulo de ascensão reta $\alpha$ (formado entre a projeção do eixo de rotação no plano inercial e o eixo inercial X).

Para o cálculo do ângulo de aspecto solar $\chi$, utiliza-se o produto escalar entre direção de incidência da luz solar $\widehat{u}$ e a direção do eixo de rotação $\hat{k}$. $\mathrm{O}$ vetor unitário $\hat{k}$ é determinada pelos ângulos $\alpha$ e $\delta$, sendo que a direção $\widehat{u}$ pode ser determinada através da ascensão reta $\alpha$ s e declinação ôs do Sol.Deste modo o ângulo $\chi$ é dado como demonstrado pelo trabalho [2]:

$\cos (\gamma)=\hat{u} \cdot \hat{k}$

$\cos (\chi)=\cos (\alpha) \cos (\delta) \cos (\alpha \mathrm{s}) \cos (\delta \mathrm{s})+\operatorname{sen}(\delta) \operatorname{sen}(\delta \mathrm{s})$

$+\operatorname{sen}(\alpha) \cos (\delta) \operatorname{sen}(\alpha s) \cos (\delta s)=\Gamma$

$\chi=\arccos (\Gamma)$

Neste trabalho o ângulo de aspecto solar é avaliado utilizando os dados fornecidos pelo Centro de Controle de Satélites do INPE (CCS/INPE) e pelos resultados obtidos em [1], utilizando o software EXCEL. As comparações a serem realizadas possibilitarão validar a abordagem numérica já desenvolvida por [1] com a utilização dos quaternios de atitude.
\end{abstract}

Palavras-chave: Ângulo de aspecto solar, raios solares, ângulo de ascensão reta, ângulo de declinação. 


\section{Referências:}

[1] M. V. CARVALHO, Propagação Numérica da Atitude de Satélites Artificiais Estabilizados por Rotação, com Uso de Quatérnions, Analisando a Influência Torques Externos. Relatório Final de Bolsa de Iniciação Científica do CNPq/INPE, INPE, São José dos Campos, 2013.

[2] M. C. ZANARDI, V. ORLANDO, P. R. S. BENTO, M. F. SILVA, Spin stabilized satellite's attitude propagation with quaternions. Journal of Aerospace Engineering, Sciences and Applications. , v. IV, p.41 - 53, 2012. 